\section{RABIES}

\section{Problems of Control}

from our Medical Virology Correspondent

RABIES is not declining; on the contrary it is spreading throughout the world especially among wild animals. Rabies virus is classified as a member of the rhabdovirus group, which contains a diverse collection of bullet-shaped RNA viruses including vesicular stomatitis virus with a bovine host, Egtved virus of rainbow trout, Marburg virus (see Nature, 233, 236 ; 1971), Sigma virus of Drosophila, Flanders-Hart Park virus with a mosquito host, potato yellow dwarf virus, maize mosaic virus and others.

Rabies virus is transmitted by contact, usually through a bite; there are no known vectors. It spreads from the site of infection along the peripheral nerves towards the central nervous system through nerve-associated tissue spaces, although this is by no means certain. Similarly, there is no explanation for the dysfunction caused by the virus in the central nervous system because only minimal cytocidal effects are usually observed in cells infected with rabies, but the host's immune response may contribute to the pathological effect.

Rabies is enzootic in all the continents except Australia and Antarctica. Many of the large islands, however, such as Britain, Cyprus, Hawaii and New Zealand are free of the disease largely because of rigidly enforced quarantine regulations concerning the entry of dogs, cats and other animals. From the standpoint of human infection, the dog has remained since ancient times the most important reservoir and transmitter of rabies. Wildlife rabies, on the other hand, constitutes the greatest problem in many areas; knowledge of the ecology of wildlife rabies, however, is fragmentary.

In Asia the pariah dog is the principal carrier of the disease, although jackals are frequently involved. Mongooses and meerkats are important rabies reservoirs in South Africa and vampire bats in Central and South America. In the United States the skunk is the most important transmitter in certain areas and bats in other regions. Sledge dogs and silver foxes are mostly affected in the Arctic region. Badgers often live in close propinquity to foxes and have been frequently infected in the current epizootic of fox rabies in central Europe (M. H. Kaplan, Nature, 221, 421 ; 1969).

The present epizootic of fox rabies in Europe is particularly disquieting. The problem is best illustrated by the following incidents. At the end of last December a 20-year-old American soldier reported to a hospital in Saigon with clinical signs suggestive of rabies. He died two weeks later. This man had played with a stray puppy on November 14 and was slightly bitten on the hand. Another serviceman also bitten by the same dog reported the incident. The dog was confined and died 3 days later of rabies. The second soldier, however, was treated successfully (Communicable Disease Centre, Zoonosis Surveillance, February 1973). In another US Air Force base in Vietnam a puppy was adopted in the officers' quarters to be registered as a mascot. The puppy was involved in a fight, was scratched on the face and ultimately devcloped rabies. Thirty-one persons, in the meantime, were possibly exposed to infection at a party held in the officers' quarters and rabies prophylaxis, unpleasant at the best of times involving up to twenty-one inoculations and not infrequently with serious side-effects, was instituted for twenty-three persons (R. Moser, Aerospace Medicine, 43, 778; 1972). These two incidents bear an important message for Britain because the principal risk of introduction of rabies to the country is by the irresponsible smuggling of dogs and cats; with the belt of rabies advancing in Western Europe this is a real hazard.

Human rabies prophylaxis is based chiefly on two types of vaccine (S. A. Plotkin and H. F. Clark, J. Infec. Dis., 123, 227; 1971). The efficacy of the nervous tissue vaccines, Semple and Fermi, has not been evaluated by controlled studies. The duck embryo vaccine has been favoured because of the lower risk of allergic encephalitis, although better antibody responses are invoked by the Semple vaccine. There are also several experimental vaccines. The Flury-HEP vaccine is a live virus passaged 180 times in chick embryos, but it elicits a poor antibody response and it is not suitable for use after exposure. Semple-type vaccines using suckling mouse brain are available in some countries. More promising are rabies vaccines prepared in tissue cultures which completely lack nervous tissue and, therefore, are not expected to be encephalogenic. The outlook for man is thus hopeful and indeed currently between 700,000 to $1,000,000$ persons are subjected annually to a rabies immunization regime; but the problem of controlling wildlife rabies remains an impossible task.

\section{NEUROPHARMACOLOGY \\ Opiate Receptor Binding}

from a Correspondent

WITH federal support of basic research plummeting, bioscientists in the United States are hastily reviewing their research for evidence of social significance. One group that will not have far to look is Snyder's team at Johns Hopkins University Medical School. In a recent issue of Science (179, 1011; 1973) Pert and Snyder announce their identification in mammalian nervous tissue of a receptor which specifically binds opiates.

Binding was demonstrated by incubating tissue homogenates with tritiumlabelled naloxone, a potent antagonist which precipitates withdrawal in humans addicted to opiates. Naloxone, rather than an agonist such as morphine, was chosen on the premise that as an antagonist its binding would be less reversible, and thus the drug-receptor complex might hang together long enough to be measured. After incubation, the homogenates were washed through a filter which trapped large

\title{
Lepore and Anti-Lepore Haemoglobins
}

THE "Lepore" and "anti-Lepore" haemoglobins are of great theoretical interest because they illustrate at a molecular level the consequences of the process of gene crossing-over. The non- $\alpha$ chain of $\mathrm{Hb}$ Lepore-Hollandia, the first example of this type of haemoglobin variant to be discovered, was found to contain $\mathrm{N}$-terminal and $\mathrm{C}$ terminal regions derived from normal $\delta$ and $\beta$ chains respectively. In 1964 Smithies showed how such a chain could arise from homologous but unequal crossing-over of the $\delta$ and $\beta$ chain genes. Haemoglobins Lepore-Boston and Lepore-Baltimore differ in the relative lengths of the $\delta$ and $\beta$ segments of the $\delta-\beta$ chain.

In Nature New Biology next Wednesday (March 28) Badr, Lorkin and Lehmann now report that the non- $\alpha$ chain of $\mathrm{Hb} \mathrm{P}-\mathrm{Nil}$ tic is a reversed or antiLepore $\beta-\delta$ chain, with the $\mathrm{N}$-terminal region derived from the $\beta$ chain and the cross-over occurring between positions 22 and 50. This clearly distinguishes it from $\mathrm{Hb}$ P-Galveston $(\beta-117, \mathrm{G} 19$, His $\rightarrow$ Arg) which has the same electrophoretic mobility.

Purified $\mathrm{Hb}$ P-Nilotic has a slightly higher oxygen affinity than $\mathrm{Hb}-\mathrm{A}$, but the haem-haem interaction and Bohr effect are very nearly identical. It is the second anti-Lepore haemoglobin to be described. The other is $\mathrm{Hb}$-Miyada, in which the $\beta-\delta$ cross-over occurs before position 22, so that its electrophoretic mobility is the same as that of $\mathrm{Hb}-\mathrm{A}_{2}$.

As Lehmann and his colleagues point out, it will be of great interest to study the biosynthesis of the $\beta-\delta$ chains of $\mathrm{Hb}$ P-Nilotic to ascertain if this occurs only in the earlier stages of erythroid cell maturation, as is the case for the $\delta$ chain of $\mathrm{Hb}-\mathrm{A}_{2}$ and the $\delta-\beta$ chain of Hb-Lepore. 